\title{
Combination effects of distinct cores in 11q13 amplification region on cervical lymph node metastasis of oral squamous cell carcinoma
}

\author{
KEISUKE SUGAHARA ${ }^{1,2}$, YUICHI MICHIKAWA ${ }^{1}$, KENICHI ISHIKAWA $^{1}$, \\ YOSHIMI SHOJI $^{1}$, MAYUMI IWAKAWA ${ }^{1}$, TAKAHIKO SHIBAHARA ${ }^{2}$ and TAKASHI IMAI ${ }^{1}$
}

${ }^{1}$ RadGenomics Project, Research Center for Charged Particle Therapy, National Institute of Radiological Sciences, Inage, Chiba 263-8555; ${ }^{2}$ Department of Oral and Maxillofacial Surgery, Tokyo Dental College, Mihama, Chiba 261-8502, Japan

Received January 25, 2011; Accepted March 30, 2011

DOI: 10.3892/ijo.2011.1094

\begin{abstract}
Lymph node metastasis (LNM) in oral squamous cell carcinoma (OSCC) is known to associate with a significant decrease of 5-year survival. Genetic factors related to the difference of the LNM status in the OSCC have been not fully elucidated. Array-based comparative genomic hybridization $(\mathrm{CGH})$ with individual gene-level resolution and real-time quantitative polymerase chain reaction (QPCR) were conducted using primary tumor materials resected from 54 OSCC patients with $(n=22)$ or without $(n=32)$ cervical LNM. Frequent gain was observed at the $11 \mathrm{q} 13$ region exclusively in patients with cervical LNM, which was confirmed by real-time QPCR experiments using 11 genes (TPCN2, MYEOV, CCND1, ORAOV1, FGF4, TMEM16A, FADD, PPFIA1, CTTN, $S H A N K 2$ and $D H C R 7)$ in this region. It was revealed that two distinct amplification cores existed, which were separated by a breakpoint between MYEOV and CCNDI in the 11q13 region. The combination of copy number amplification at CTTN (core 2) and/or TPCN2/MYEOV (core 1), selected from each core, was most significantly associated with cervical LNM ( $\mathrm{P}=0.0035)$. Two amplification cores at the $11 \mathrm{q} 13$ region may have biological impacts on OSCC cells to spread from the primary site to local lymph nodes. Further study of a larger patient series should be conducted to validate these results.
\end{abstract}

\section{Introduction}

Oral squamous cell carcinoma (OSCC) is a common malignancy that affects 300,000 individuals per year worldwide (1). Despite

Correspondence to: Dr Takashi Imai, RadGenomics Project, Research Center for Charged Particle Therapy, National Institute of Radiological Sciences, Anagawa, Inage, Chiba 263-8555, Japan

E-mail: imait@nirs.go.jp

Key words: squamous cell carcinoma, lymph node metastasis, copy number abnormality, arrayCGH, 11q13 diagnostic and therapeutic improvements in surgical techniques, radiotherapy, and chemotherapy, the prognosis of OSCC has remained dismal, as approximately $50 \%$ of patients die within 5 years $(1,2)$. Studies have shown that cervical lymph node metastasis (LNM) is strongly correlated with poor prognosis, such as increased risk of distant metastasis, recurrence at the primary site, and reduction in the 5-year survival rate (3-5). Sentinel lymph node biopsy is a technique that facilitates detection of the LNM and reduction of morbidity in patients. Common diagnostic technologies such as computed tomography (CT) and magnetic resonance imaging (MRI) have shown unsatisfactory sensitivity and specificity for the detection of LNM. Though, the sensitivity of $18 \mathrm{~F}-\mathrm{FDG}$ PET is significantly higher than that of $\mathrm{CT} / \mathrm{MRI}$. Their specificities appeared to be similar. Visual correlation of PET and CT/MRI showed a trend of increased diagnostic accuracy; however, its sensitivity is still not high enough to replace pathologic lymph node staging based on surgical dissection (6).

The mechanisms by which OSCC cells spread from the primary site to cervical lymph nodes is not fully understood. A mouse model of the cervical LNM was established by Sun et al (7). Among three human OSCC cell lines implanted into the nude mouse, one cell line exhibited significantly high rate of LNM, indicating important roles of inherent differences of OSCC cells in the potential of LNM. Cytogenetic analyses in conjunction with molecular genetics analyses by many research groups have revealed accumulation of genetic abnormalities during development and/or progression of OSCC (8). Recent advances in tumor molecular biology have revealed chromosomal rearrangements at the level of individual genes in the whole human genome.

Because chromosomal abnormalities can influence individual cancer characteristics, comparative genomic hybridization $(\mathrm{CGH})$ has been used extensively to find LNM-associated chromosomal abnormalities in OSCC patients (9). Such CGH studies have identified several chromosomal regions, including 11q13, but the regions have yet to be proven as reliable prognostic markers. Array-based CGH using BAC clones $(10,11)$ has improved the resolution of analysis to the level of several hundred kilo base regions. Currently, arraybased CGH using in situ synthesized oligonucleotides (12) is 
available to provide superior resolution at the level of individual genes in the whole human genome. Xu et al (13) reported on the correlation between DNA copy number abnormality and expression in 11q13.2-11q13.3 using both the array-based CGH and the gene expression microarray techniques, and identified genes associated with poor survival in metastatic OSCC patients.

In this study, an oligonucleotide array-based CGH was applied to screen LNM-associated abnormalities of genes in a subpopulation of Japanese OSCC patients. The purpose of this study was to identify a reliable prognostic marker related to LNM in this population. Using a larger patient series, further mapping of corresponding gene regions was conducted by real-time quantitative PCR (QPCR) to elucidate the correlation among those regions.

\section{Patients and methods}

Patient characteristics. Fifty-four Japanese patients with OSCC were included in the present study. Surgical resection of primary tumors and marginal normal tissues from all patients was performed at the Hospital of Tokyo Dental College, Chiba, Japan, between July 1999 and September 2006. The ethics committees of the Tokyo Dental College and the National Institute of Radiological Sciences approved the present study. Informed consent was obtained from each patient before surgical resection.

Staging of tumors was performed according to the International Union Against Cancer TNM staging system (14). Cervical LNM during the 24-month follow-up period was evaluated by both CT and MRI. In case of a positive signal, metastasis was further confirmed by histopathological examination of resected tissues. Patients absent of any cervical LNM for 24 months after surgery were considered metastasisfree. Patients with distant metastasis at the time of clinical examination or those receiving preventive radiotherapy or chemotherapy were excluded from this study. Detailed patient characteristics are shown in Table I.

Primary tumor samples. Resected primary tumor tissues were divided into two pieces. One piece was frozen immediately in liquid nitrogen and stored at $-80^{\circ} \mathrm{C}$. The other one was fixed in $10 \%$ formalin for histopathological examination. The resected marginal normal tissues were frozen immediately in liquid nitrogen and stored at $-80^{\circ} \mathrm{C}$.

DNA extraction and quantification. DNA from the frozen tumor and marginal normal tissues was extracted using the QIAamp tissue kit (Qiagen, Hilden, Germany) according to the manufacturer's instructions. The amount of extracted DNA was quantified by PicoGreen dsDNA quantitation reagent (Invitrogen, Carlsbad, CA).

Array-based CGH. Array-based CGH for primary tumor samples was performed using a Human Genome CGH Microarray Kit 44K (Agilent Technologies, Santa Clara, CA), which contains in situ synthesized 60-mer oligonucleotides representing 42,494 unique probes for human genes. Labeling and hybridization were performed essentially as described elsewhere (19), with the following modifications. We amplified $100 \mathrm{ng}$ each of reference (male or female human genomic DNA;
Table I. Clinical characteristics of the 54 OSCC patients.

\begin{tabular}{|c|c|c|c|}
\hline & $\begin{array}{c}\text { LNM } \\
\text { present }\end{array}$ & $\begin{array}{c}\text { LNM } \\
\text { absent }\end{array}$ & \\
\hline & $(n=22)$ & $(n=32)$ & P-value \\
\hline Age (years; mean \pm SD) & $60 \pm 10$ & $60 \pm 14$ & 0.718 \\
\hline Gender & & & 0.877 \\
\hline Male & $13(59 \%)$ & $17(53 \%)$ & \\
\hline Female & $9(41 \%)$ & $15(47 \%)$ & \\
\hline
\end{tabular}

Site

$\begin{array}{lrrrr}\text { Tongue } & 13(59 \%) & 13(41 \%) \\ \text { Gingiva } & 4(18 \%) & 16(50 \%) \\ \text { Palate } & 1 & (5 \%) & 1 & (3 \%) \\ \text { Buccal mucosa } & 2 & (9 \%) & 1 & (3 \%) \\ \text { Oral floor } & 2 & (9 \%) & 1 & (3 \%)\end{array}$

Stage

I $\quad 3(14 \%) \quad 11(35 \%)$

II $\quad 3(14 \%) \quad 16(50 \%)$

III $8(36 \%) \quad 2 \quad(6 \%)$

IV $8(36 \%) \quad 3(9 \%)$

T classification

0.528

$\mathrm{T}_{1}$

$\mathrm{T}_{2}$

$5(23 \%) \quad 11(35 \%)$

$11(50 \%) \quad 19(59 \%)$

$\mathrm{T}_{3}$

$2(9 \%) \quad 1 \quad(3 \%)$

$\mathrm{T}_{4}$

$4(18 \%)$

$1(3 \%)$

$\mathrm{N}$ classification

0.0002

$\begin{array}{llll}\mathrm{N}_{0} & 6(27 \%) & 28(88 \%) \\ \mathrm{N}_{1} & 9(41 \%) & 2 & (6 \%) \\ \mathrm{N}_{2} & 7(32 \%) & 2 & (6 \%) \\ \mathrm{N}_{3} & 0(0 \%) & 0 & (0 \%)\end{array}$

${ }^{\text {a}}$ For age, results of Mann-Whitney U test; Fisher's exact test for other variables. OSCC, oral squamous cell carcinoma; LNM, lymph node metastasis confirmed by histopathological examination within the 24-month follow-up period.

Promega, Madison, WI) and tumor DNA with Phi29 DNA polymerase according to the supplier's protocols (Qiagen); DNA was then digested with $A l u \mathrm{I}(50 \mathrm{U})$ and $R s a \mathrm{I}(50 \mathrm{U}$; Promega) for $2 \mathrm{~h}$ at $37^{\circ} \mathrm{C}$. Digests were filtered using the QIAprep Spin Miniprep kit (Qiagen) and then verified with Bioanalyzer (Agilent Technologies). Fluorescent labeling reactions to make hybridization probes were performed with $7 \mu \mathrm{g}$ of purified restricted DNA using a BioPrime array CGH genomic labeling kit (Invitrogen), according to the manufacturer's instructions, in a volume of $50 \mu \mathrm{l}$ with a modified dUTP pool containing $120 \mu \mathrm{M}$ each of dATP, dGTP, 
Table II. Oligonucleotide sequences used for real-time QPCR.

\begin{tabular}{|c|c|c|c|c|}
\hline $\begin{array}{l}\text { Gene/primer } \\
\text { name }\end{array}$ & $\begin{array}{l}\text { Accession } \\
\text { no. }\end{array}$ & Type & Primer sequence & $\begin{array}{l}\text { Product } \\
\text { size (bp) }\end{array}$ \\
\hline \multicolumn{5}{|c|}{$11 q 13$ gene region } \\
\hline TPCN2 & NM_139075 & $\begin{array}{l}\text { Forward } \\
\text { Reverse }\end{array}$ & $\begin{array}{l}\text { 5'-CAGTTGTTTTCTCTTGTTGCTG } \\
\text { 5'-TCCCTTGTCCTCTGACTTGTTT }\end{array}$ & 75 \\
\hline MYEOV & NM_138768 & $\begin{array}{l}\text { Forward } \\
\text { Reverse }\end{array}$ & $\begin{array}{l}\text { 5'-CACTTCCCTGACCCCAGTAA } \\
\text { 5'-ATGAGCAACGAGTCCCTGTC }\end{array}$ & 124 \\
\hline$C C N D 1$ & NM_053056 & $\begin{array}{l}\text { Forward } \\
\text { Reverse }\end{array}$ & $\begin{array}{l}\text { 5'-GAGGTGGCAAGAGTGTGGAG } \\
\text { 5'-CCTGGAAGTCAACGGTAGCA }\end{array}$ & 150 \\
\hline ORAOVI & NM_153451 & $\begin{array}{l}\text { Forward } \\
\text { Reverse }\end{array}$ & $\begin{array}{l}\text { 5'-AAGTAGGGTCATCATAAGGGAAT } \\
\text { 5'-AGGAAGCCAGCAGCATAGC }\end{array}$ & 150 \\
\hline$F G F 4$ & NM_002007 & $\begin{array}{l}\text { Forward } \\
\text { Reverse }\end{array}$ & $\begin{array}{l}\text { 5'-ATGCTCCACGCCATACTACA } \\
\text { 5'-GTGTGCTGCTATTCTGTGTTTT }\end{array}$ & 77 \\
\hline TMEM16А & NM_018043 & $\begin{array}{l}\text { Forward } \\
\text { Reverse }\end{array}$ & $\begin{array}{l}\text { 5'-CAGCATTTCCAACCCACAG } \\
\text { 5'-GCACTCCAGACAGCCAGATA }\end{array}$ & 136 \\
\hline$F A D D$ & NM_003824 & $\begin{array}{l}\text { Forward } \\
\text { Reverse }\end{array}$ & $\begin{array}{l}\text { 5'-AGCCATTCAGTCACCAATCA } \\
\text { 5'-GCTGTTCTGTCCATCCTGTC }\end{array}$ & 98 \\
\hline PPFIAI & NM_003626 & $\begin{array}{l}\text { Forward } \\
\text { Reverse }\end{array}$ & $\begin{array}{l}\text { 5'-TGCTTTGGAAGATAAGGTAAGTT } \\
\text { 5'-TGGCAGAGGGTGGGAAA }\end{array}$ & 120 \\
\hline CTTN & NM_005231 & $\begin{array}{l}\text { Forward } \\
\text { Reverse }\end{array}$ & $\begin{array}{l}\text { 5'-TTCCTCATTGGATTACTGTGTTT } \\
\text { 5'-TACСTTTCTTTCCGCTTGGA }\end{array}$ & 73 \\
\hline SHANK2 & NM_133266 & $\begin{array}{l}\text { Forward } \\
\text { Reverse }\end{array}$ & $\begin{array}{l}\text { 5'-GCGTGCATCCAAGAAATGCG } \\
\text { 5'-AGGTTCAGTAGACTCGAATGG }\end{array}$ & 58 \\
\hline DHCR7 & NM_001360 & $\begin{array}{l}\text { Forward } \\
\text { Reverse }\end{array}$ & $\begin{array}{l}\text { 5'-GCGGAGGTAGGTCTTTCACA } \\
\text { 5'-CCATTTCGCCATAGAACCAT }\end{array}$ & 106 \\
\hline \multicolumn{5}{|l|}{ Reference } \\
\hline$N A G K$ & NM_017567 & $\begin{array}{l}\text { Forward } \\
\text { Reverse }\end{array}$ & $\begin{array}{l}\text { 5'-TGGGCAGACACATCGTAGCA } \\
\text { 5'-CACСТTCACTCCCАCСТCAАC }\end{array}$ & 66 \\
\hline
\end{tabular}

and dCTP; $60 \mu \mathrm{M}$ dTTP; and $60 \mu \mathrm{M}$ Cy5-dUTP or Cy3-dUTP (Perkin-Elmer, Waltham, MA). Labeled reference and tumor DNA probes were subsequently mixed and filtered with a Microcon YM-30 column (Millipore, Billerica, MA) then verified with Bioanalyzer (Agilent Technologies). To the mixtures were added $50 \mu \mathrm{g}$ of Human Cot-1 DNA (Invitrogen)/ Agilent 10X Blocking Agent/Agilent 2X hybridization buffer. Before hybridization to the array, the hybridization mixtures were denatured at $95^{\circ} \mathrm{C}$ for $3 \mathrm{~min}$ then incubated at $37^{\circ} \mathrm{C}$ for $30 \mathrm{~min}$. The mixtures were centrifuged at $17,900 \mathrm{x}$ g for $1 \mathrm{~min}$ to remove any precipitate and then applied to the array using an Agilent microarray hybridization chamber. Hybridization was carried out for $40 \mathrm{~h}$ at $65^{\circ} \mathrm{C}$ in a rotating oven (Robbins Scientific, Mountain View, CA) at $20 \mathrm{rpm}$. The arrays were then disassembled in $0.5 \mathrm{X} \mathrm{SSC} / 0.005 \%$ Triton X-102 at room temperature then washed for $5 \mathrm{~min}$ at room temperature in wash 1 , followed by $1 \mathrm{~min}$ at $37^{\circ} \mathrm{C}$ in $0.1 \mathrm{X} \mathrm{SSC} / 0.005 \%$ Triton $\mathrm{X}-102$ (wash 2). Slides were dried and scanned using an Agilent G2565B DNA microarray scanner.

Image data analysis. Array-based CGH images were analyzed using Feature Extraction software (Ver. 8.5.1.1, Agilent Techno- logies). The linear normalization method was applied to the all datasets, and signals from negative control features were used for background subtraction. Datasets resulting from dye-swap experiments were averaged and then further analyzed using CGH Analytics software (Ver. 3.4, Agilent Technologies).

Real-time QPCR. Real-time QPCR was performed using tumor or marginal normal tissue samples with SYBR Green I fluorescence detection on a LightCycler 480 (Roche Diagnostics, Basel, Switzerland). Oligonucleotide primers for real-time QPCR were designed using Primer 3 software (Whitehead Institute for Biomedical Research), and uniqueness in the human genome was checked by a BLAST search. Nucleotide sequences of oligonucleotide primers are listed in Table II. The 20- $\mu 1$ reaction mixture consisted of $10 \mu \mathrm{l} 2 \mathrm{X}$ iQ SYBR Green Supermix (Bio-Rad Laboratories, Hercules, CA), $2.5 \mathrm{ng}$ genomic DNA, and $800 \mathrm{nM}$ of each PCR primer. The reaction mixtures were heated at $95^{\circ} \mathrm{C}$ for $10 \mathrm{~min}$ and then subjected to 40 rounds of two-step temperature cycling $\left[95^{\circ} \mathrm{C}\right.$ for $15 \mathrm{sec}$ and $65^{\circ} \mathrm{C}$ for $\left.60 \mathrm{sec} ;(15)\right]$. The crossing point for each amplification curve was determined by the second derivative 


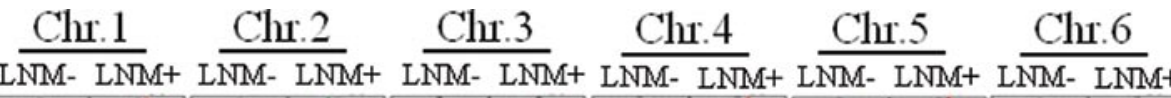

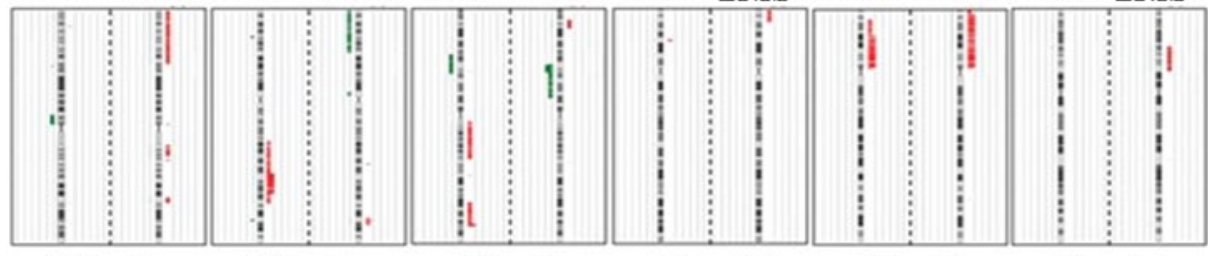

Chr.7 Chr.8 Chr.9 Chr.10 Chr.11 Chr.12

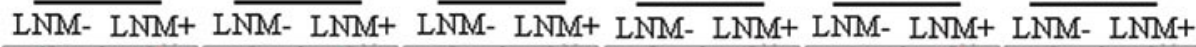

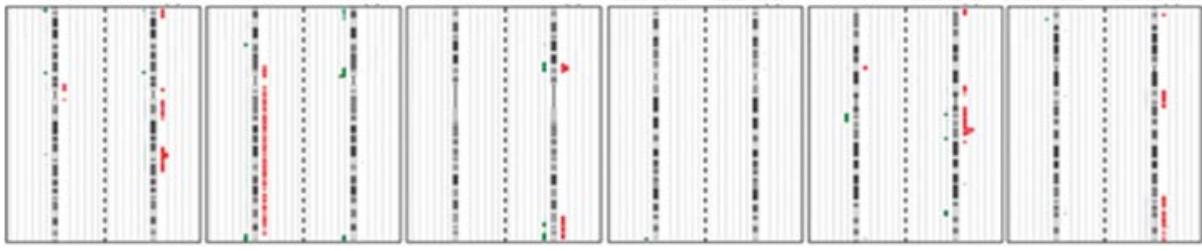

Chr.13 Chr.14 Chr.15 Chr.16 Chr.17 Chr.18

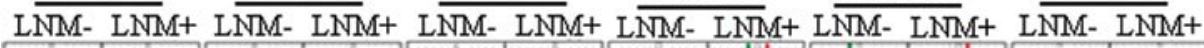

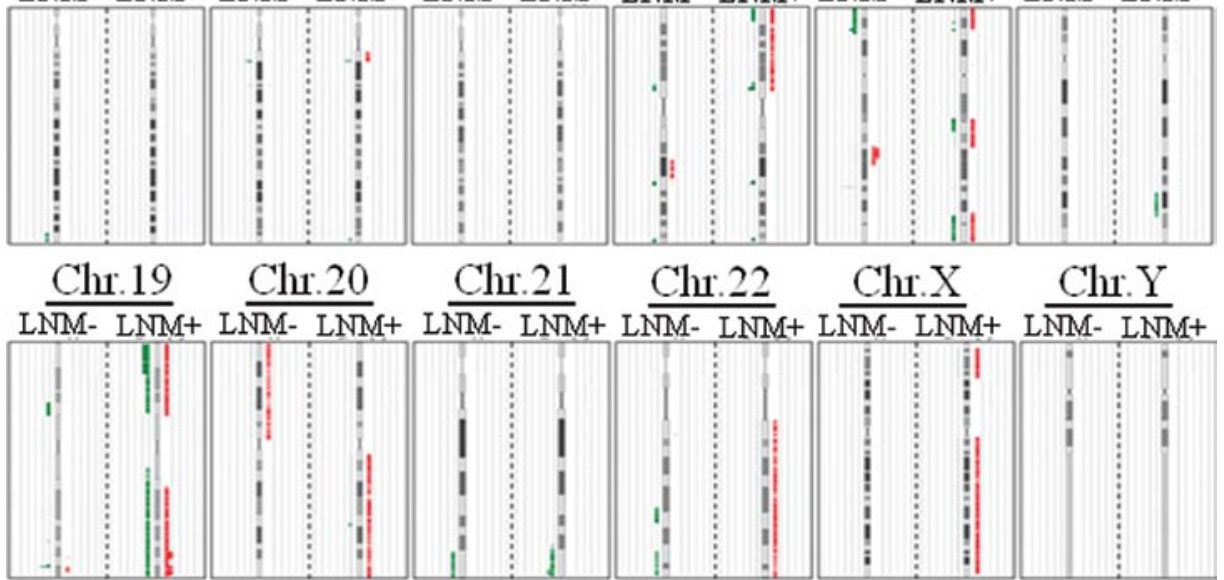

Figure 1. Array-based CGH karyogram of tissues from 20 OSCC patients.Multiple displacement amplification of tumor DNA by Phi29 DNA polymerase yielded almost 18 -fold amplification on average. The gel electrophoresis pattern of the all amplified products met the criteria of the manufacturer (Agilent Technologies). The dye-swap method with sex-matched reference DNA was applied for two-color array-based CGH. Duplicated data by the dye-swap experiments were combined using CGH Analytics Software. Two consecutive probes with $\log _{2}$ ratio $>0.59$ (gain) are shown by a red bar and those having a $\log _{2}$ ratio $<-0.42$ (loss) are shown by a green bar. The length of each bar indicates frequency. LNM(-), patient group without cervical lymph node metastasis; LNM(+), group with cervical LNM.

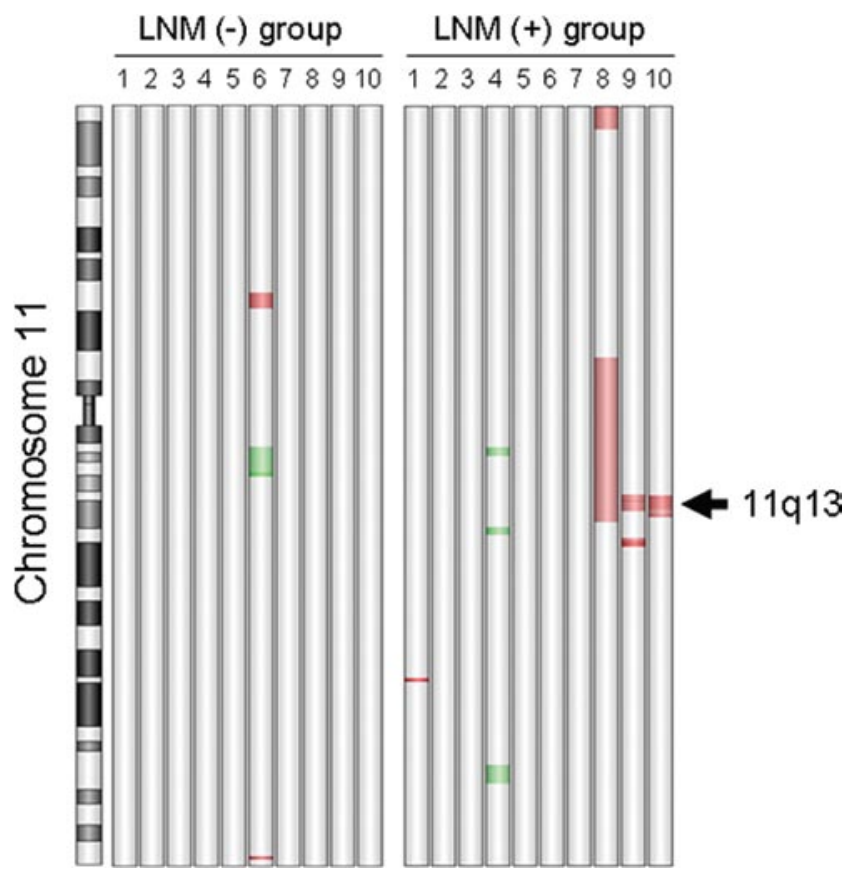

maximum method. The standard curve method using separate reaction wells was applied for relative quantification. The copy numbers are presented as the $\log _{2}$ ratio of each target locus in tumor normalization to an internal reference loci (N-acetylglucosamine kinase, NAGK; 16) and relative to the reference DNA, calculated as follows: copy number $=($ target loci dosage of tumor DNA/target loci dosage of reference DNA)/(reference loci dosage of tumor DNA/reference loci dosage of reference DNA). A $\log _{2}$ ratio $>0.59$ was set as the cutoff value for copy number amplification.

Figure 2. Schematic diagram of individual gain and loss regions on chromosome 11. Chromosomal regions in which two consecutive probes showed a gain $\left(\log _{2}\right.$ ratio $\left.>0.59\right)$ are shown in red and those that showed a loss $\left(\log _{2}\right.$ ratio $<-0.42)$ are shown in green. The most frequent gain region at $11 \mathrm{q} 13$ observed exclusively in the LNM (+) group (patients with cervical lymph node metastasis) is indicated by an arrow. 

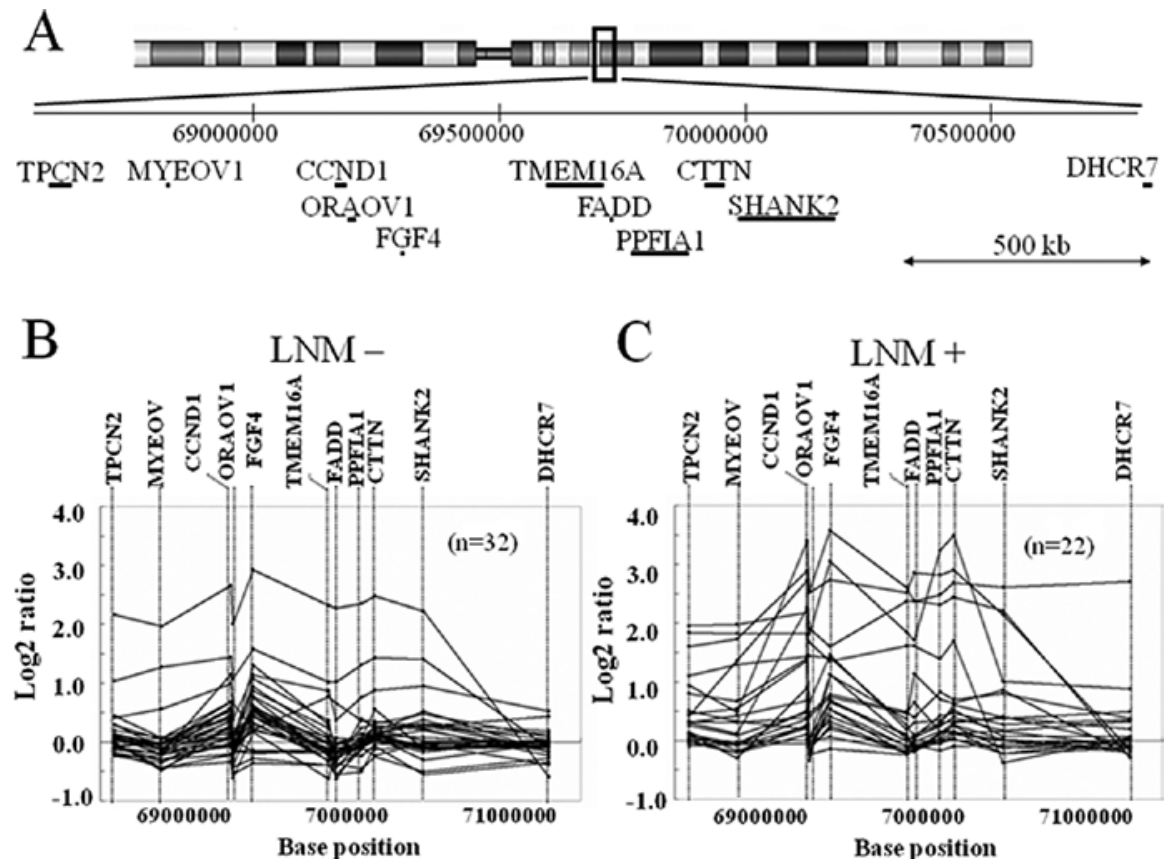

Figure 3. Detailed quantitative assessment of genes in the 11q13 region. (A) An approximately 2.2-Mb comprehensive physical map of the 11q13 region and target genes. The $\log _{2}$ ratio of individual gene quantity relative to reference locus (NAGK, chromosome 2) is shown for 32 OSCC patients without cervical LNM (B) and 22 OSCC patients with cervical LNM (C). Location of the PCR amplicon for each gene is indicated by a broken vertical $\operatorname{line}_{\text {. A }} \log _{2}$ ratio $>0.59$ indicated copy number amplification.

Statistical analysis. The association between copy number amplification and LNM was assessed by Fisher's exact test. The LNM-free survival curve was plotted by the Kaplan-Meier method using StatView version 5.0 (SAS Institute, Cary, NC). Pearson's correlation coefficients were used to determine the degree of correlation between the incidence data of two genes. The log+rank test was used to compare differences in LNM-free survival between the two groups. A $\mathrm{P}<0.05$ was considered to indicate statistical significance.

\section{Results}

This study included 54 patients who had undergone surgical resection of primary OSCC. Twenty-two patients had histopathologically confirmed cervical LNM at the time of diagnosis or during the 24-month follow-up period (LNM present). Patients with distant metastasis at the time of diagnosis were not included in this study. Mean age, gender, tumor site, and $\mathrm{T}$ classification were not significantly different between the two groups (Table I).

Array-based $\mathrm{CGH}$ analysis. Ten patients from each group (LNM present or LNM absent) were subjected to array-based CGH analysis to screen for LNM-associated gene abnormalities in this population. A total of 231 of 42,494 probes were eliminated from the dataset because they exceeded the limit of deviation between the dye-swap duplicated data in at least one patient. The array-based CGH karyogram is shown in Fig. 1. Previous CGH studies have shown that gains in 3q, 5p, 8q, 9q, 11q, and 20q and losses in 3p, 4q, 8p, 9p, and 18q are common chromosomal alterations in OSCC patients (17-20). A total of 48 gain regions including six previously reported segments $(3 q, 5 p, 8 q, 9 q, 11 q$, and $20 q)$ and 31 loss regions including four previously reported segments $(3 p, 8 p, 9 p$, and $18 q)$ were found in the LNM-present group. In contrast, 32 gain regions including three previously reported segments (3q, 5p, and 8q) and 26 loss regions including three previously reported segments (3p, 8p, and 21q) were found in the LNM-absent group. Among these, gain at the $11 \mathrm{q} 13$ region was the only chromosomal abnormality that reached a frequency of $30 \%$ exclusively in one group (LNM present; Fig. 2).

Assessment of genes in the 11 113 region by QPCR. To evaluate array-based CGH data at the 11q13 region, real-time QPCR was performed using non-amplified genomic DNA as a template. Initially, seven PCR primer sets located respectively in TPCN2, MYEOV, ORAOV1, PPFIA1, CTTN, SHANK2, and DHCR7 of the $11 \mathrm{q} 13$ region were successfully designed to meet the criteria for reliable quantification at exactly the same position as corresponding probes on the CGH array (Table II and Fig. 3A). One PCR primer set was designed in a housekeeping gene, NAGK located on chromosome 2, as a reference for normalization. Real-time QPCR analysis was performed with the above primer sets using genomic DNA of the 20 previously analyzed patients and of sex-matched references, resulting in generation of 140 overlapping data. The correlation coefficient between the array-based CGH data and real-time QPCR data was 0.68 , indicating moderate reproducibility between the two methods. Additional PCR primer sets were designed in adequate place of genes such as CCND1, FGF4, TMEM16A, and $F A D D$, that initial primer design at the probe site failed to meet the criteria (Table II and Fig. 3A). These 11 primer sets were then used for real-time QPCR analysis of all 54 patients. As shown in Fig. 3B and C, the individual amplification regions spanning from CCND1 to CTTN showed regional variations in the degree of amplification and indicated genetic 
Table III. Number of patients who had amplified genes.

\begin{tabular}{lcccr}
\hline & \multicolumn{4}{c}{ Number of amplified genes in the 11q13 region ${ }^{\text {a }}$} \\
\cline { 2 - 5 } & 0 & 1 & 2 & $>3$ \\
\hline LNM absent $(\mathrm{n}=32)$ & $21(65.6 \%)$ & $5(15.6 \%)$ & $2(6.3 \%)$ & $4(12.5 \%)$ \\
LNM present $(\mathrm{n}=22)$ & $7(31.8 \%)$ & $3(13.6 \%)$ & $2(9.1 \%)$ & $10(45.5 \%)$ \\
Total & 28 & 8 & 4 & 14 \\
\hline
\end{tabular}

${ }^{\mathrm{a}} \log _{2}$ ratio $>0.59$ indicated copy number amplification in the $11 \mathrm{q} 13$ region. $\mathrm{LNM}$, lymph node metastasis confirmed by histopathological examination within the 24-month follow-up period.

\begin{tabular}{|c|c|c|c|c|c|c|c|c|c|c|c|}
\hline $\mathrm{TPCN}_{2}$ & & & & & & & & & & $\mathrm{R}^{2}$ & $>0.75$ \\
\hline MYEOV & 0.88 & & & & & & & & & & \\
\hline $\mathrm{CCNDI}$ & 0.60 & 0.63 & & & & & & & & & \\
\hline ORAOVI & 0.77 & 0.76 & 0.77 & & & & & & & & \\
\hline FGF4 & 0.50 & 0.48 & 0.76 & 0.74 & & & & & & & \\
\hline TMEM16A & 0.71 & 0.67 & 0.78 & 0.90 & 0.76 & & & & & & \\
\hline FADD & 0.71 & 0.71 & 0.74 & 0.84 & 0.65 & 0.89 & & & & & \\
\hline PPFIAI & 0.59 & 0.67 & 0.80 & 0.85 & 0.79 & 0.90 & 0.87 & & & & \\
\hline CTTN & 0.59 & 0.65 & 0.80 & 0.83 & 0.79 & 0.88 & 0.84 & 0.98 & & & \\
\hline SHANK2 & 0.46 & 0.38 & 0.61 & 0.64 & 0.69 & 0.75 & 0.67 & 0.72 & 0.68 & & \\
\hline DHCRT & 0.02 & 0.02 & 0.26 & 0.19 & 0.25 & 0.16 & 0.11 & 0.16 & 0.16 & 0.15 & \\
\hline & $\mathrm{TPCN2}$ & MYYEOV & CCNDI & ORAOVI & FGF4 & TMERM16A & FADD & PPFLAI & CTIN & SHANK2 & DHCRT \\
\hline
\end{tabular}

Figure 4. Pearson correlation coefficients between pairs of target genes. There were two hypothetical cores in the 11q13 region according to R2 values. Core 1 contains two genes (TPCN2 and MYEOV) and core 2 contains seven genes (CCND1, ORAOV1, FGF4, TMEM16A, FADD, PPFIA1, and CTTN).

complexity and diversity in this OSCC patients. In 30 of the 32 LNM-absent patients, we found no significant gene amplification in the region from TPCN2 to DHCR7. DHCR7 copy number amplification was observed only in two LNMpresent patients. Amplification of at least one gene was observed in $26(48.1 \%)$ of all 54 patients: 15 with cervical LNM $(68.2 \%)$ and 11 without cervical LNM (34.4\%, $\mathrm{P}=0.0146)$. Amplification of at least two genes was observed in 18 (33.3\%) of the patients: 12 with cervical LNM (54.5\%) and 6 without cervical LNM (18.8\%, P=0.0088; Table III).

QPCR analysis of DNA from marginal normal tissues was performed in 30 patients whose DNA samples were available. The $\log _{2}$ ratio was measured for CCND1, PPFIA1, CTTN, and $S H A N K 2$, and no copy number amplification of these genes was observed in marginal normal tissues. The $\log _{2}$ ratio data using reference genomic DNA (Promega) and the $\log _{2}$ ratio data using DNA from marginal normal tissue indicated generally high consistency $\left(\mathrm{R}^{2}=0.89\right.$; data not shown).

Evaluation of amplification core structure in the 11q13 region. The OSCC patients exhibit various patterns of copy number amplifications and the minimal overlapping region of ampli- fication was $\sim 0.77 \mathrm{Mb}$, including nine known genes (CCND1, ORAOV1, FGF19, FGF4, FGF3, TMEM16A, FADD, PPFIA1, and $C T T N$ ). To elucidate the relationships among genes within this amplification region, analyses of correlation between sets of gene pairs were performed. According to the resulting $\mathrm{R}^{2}$ values, there were two hypothetical cores in the $11 \mathrm{q} 13$ region: core 1 spanned from TPCN2 to MYEOV and core 2 spanned from $C C N D 1$ to $C T T N$ (Fig.4). The highest $\mathrm{R}^{2}$ value was between CTTN and PPFIAI $\left(\mathrm{R}^{2}=0.98\right)$. Presence of two cores in the 11q13 amplification region indicates that a breakpoint might be located at the 5' terminus of CCND1 gene.

Prognostic value of 11 q13 copy number amplification for cervical LNM. To examine the prognostic value of 11q13 copy number amplification for cervical LNM, we first evaluated the association of amplification of individual genes with cervical LNM. Because no LNM-absent patient showed amplification of $D H C R 7$, we excluded this gene from the analysis. CCND1, $F G F 4$, and $C T T N$ showed statistically significant associations with cervical LNM $(\mathrm{P}<0.05$; Table IV). We next investigated the association between prognosis and combinations of various amplified genes. Combination of copy number amplification 
Table IV. Significance of candidate genes within the 11q13 region as prognostic markers of cervical LNM.

\begin{tabular}{lc}
\hline Gene LNM(+) & P-value \\
\hline Single marker & \\
TPCN2 & 0.051 \\
MYEOV & 0.051 \\
CCND1 & 0.020 \\
ORAOV1 & 0.071 \\
FGF4 & 0.027 \\
TMEM16A & 0.461 \\
FADD & 0.071 \\
PPFIA1 & 0.071 \\
CTTN & 0.036 \\
SHANK2 & 0.136 \\
Combination of markers ${ }^{\mathrm{b}}$ & \\
Core 1_core2 & \\
TPCN2_CTTN & \\
MYEOV_CTTN & 0.0035 \\
TPCN2_PPFIA1 & 0.0035 \\
MYEOV_PPFIA1 & 0.0089 \\
TPCN2_FADD & 0.0089 \\
MYEOV_FADD & 0.0089 \\
TPCN2_SHANK2 & 0.0089 \\
MYEOV_SHANK2 & 0.0089 \\
Core 2_core 2 & 0.0089 \\
CCND1_FADD & \\
CCND1_PPFIA1 & 0.0036 \\
CCND1_CTTN & \\
CCND1_SHANK2 & \\
ORAOV1_FADD & 0.0088 \\
\hline
\end{tabular}

${ }^{\mathrm{a}}$ Fisher's exact test. ${ }^{\mathrm{b}}$ Only marker sets that had $\mathrm{P}<0.01$ are shown. ${ }^{\mathrm{c}}$ Core 1 and core 2 were in the $11 \mathrm{q} 13$ amplification region, with the breakpoint located at approximately $11.32 \mathrm{~kb}$ centromeric to CCND1.

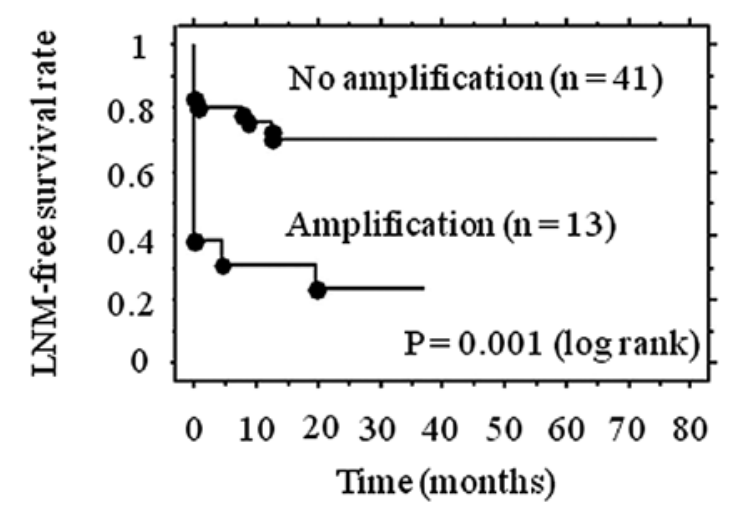

Figure 5. Cervical LNM-free survival plotted by the Kaplan-Meier method. Cervical LNM-free survival analysis of all OSCC patients based on amplification status showed a significant difference in survival time between the 13 patients with amplification of core 2 gene $(C T T N)$ and/or core 1 gene (TPCN2/ MYEOV) versus the 41 patients without amplification of these three genes. at CTTN (core 2) and/or TPCN2/MYEOV (core 1), which were selected from each core separated by the novel breakpoint, showed the strongest association with cervical LNM $(\mathrm{P}=0.0035)$. When cervical LNM-free survival was plotted by the KaplanMeier method, the data showed that LNM was significantly higher in those patients with CTTN and/or TPCN2/MYEOV amplification ( $\mathrm{P}=0.001$; Fig. 5).

\section{Discussion}

The 11q13 region contains numerous functional genes relevant to metastasis or poor prognosis (21-23). Thus, understanding the variable contributions of these genes, as shown by the non-uniform nature of their amplification, may be a key for more precise prediction of metastasis and survival. Our findings revealed two cores in the $11 \mathrm{q} 13$ region, core 1 (TPCN2, MYEOV) and core 2 (CCND1, ORAOV1, FGF4, TMEM16A, FADD, PPFIAI, and CTTN), with a breakpoint at $11.32 \mathrm{~kb}$ centromeric to $C C N D 1$. Our analyses also indicated that two-gene combinations can be used as LNM predictive markers (Fig. 5 and Table IV).

Studies have shown that LNM is strongly correlated with poor prognosis (3-5). Based on chromosomal CGH and bacterial artificial chromosome $\mathrm{CGH}$ arrays, studies have reported several genes as prognostic markers for $\operatorname{LNM}(9,24)$. We used high-resolution array-based CGH as an initial screening method, and to our knowledge, this is the first report of an oligonucleotide array-based CGH for primary Japanese OSCC. Our findings concur with those of other reports, namely that a gain in the 11q13 region was the only chromosomal abnormality that reached a frequency of $30 \%$ exclusively in the LNM-present group (Fig. 2).

Breaking of the DNA double strand is the initial step of gene amplification, and proto-oncogenes are clustered around recombination hotspots or fragile sites. The homogeneously staining region (HSR) involving 11q13 includes amplified genes from this chromosome segment (25) and carries a relatively poor prognosis in OSCC patients $(26,27)$. Several reports have suggested that HSR formation result from breaks in fragile sites, based on findings that gaps or breaks form at these sites in metaphase chromosomes when cells are grown under conditions that interfere with DNA replication or repair (28-30). The breakage of DNA at these fragile sites led Coquelle et al (28) to propose the breakage-fusion-bridge cycle model. Recently, Reshmi et al (31) provided experimental evidence that 11q13 gene amplification in OSCC cells occurs via breakage-fusionbridge cycles. It is of great interest to elucidate detail of breakage structure between the two core segments in future study.

In this study, TPCN2 and MYEOV were indentified biomarker of LNM, and theses two genes showed high correlation (Fig. 4). $\mathrm{Xu}$ et al (13) provided that correlation between DNA copy number abnormality and expression in 11q13.2-11q13.3.TPCN2 showed high correlation between DNA copy number abnormality and expression, while $M Y E O V$ showed no significant correlation. Thus TPCN2 might be functionally important, whereas the copy number abnormality of $M Y E O V$ might act as just surrogate marker.

Our findings indicate that $C T T N$ amplification has a high prognostic value in OSCC patients. CTTN is an actin-associated scaffolding protein, which binds and activates the actin-related 
protein $2 / 3$ complex, and thus regulates the branched actin networks in the formation of dynamic cortical actin-associated structures (32,33). Functional analysis in breast cancer and head and neck squamous cell carcinoma patients has revealed that CTTN promotes invasiveness of cancer cells $(21,34)$. Huang et al (35) reported no association between LNM and amplification status or expression of 10 genes in the 11 q13 region in OSCC patients, although another OSCC study indicated that both ORAOVI and CTTN amplifications were significantly associated with the presence of LNM (36). ORAOVI regulates cell cycle and apoptosis in cervical cancer HeLa cells. Furthermore amplification and overexpression of CTTN was correlated with LNM in esophageal squamous cell carcinoma patients (23).

Table IV lists other candidate genes that may be associated with LNM. FGF4 was reported to have an association with LNM in OSCC patients (24). Although cDNA microarray analysis revealed overexpression of FADD in OSCC patients, no correlation was found with cervical LNM (37). In lung adenocarcinoma patients increased $F A D D$ mRNA and protein were significantly associated with poor outcome (38).

We used 20 patients with $\mathrm{T}_{1}$ or $\mathrm{T}_{2}$ group for array-based CGH. We unexpectedly found that two patients in the LNM-absent group also showed 11q13 amplification (Fig. 3 and Table III). Because there is a possibility of cervical LNM in the future, it is important to follow-up carefully.

We refined the comprehensive physical map of the 11q13 amplification region and found two core regions separated by a novel breakpoint. Copy number amplification of CTTN (core 2) and/or TPCN2/MYEOV (core 1) in the 11q13 region was strongly associated with LNM in OSCC patients. Detailed assessment of selected loci followed by real-time QPCR appears to be a good strategy for identifying genetic markers in regions with complicated alterations, as is the case with 11q13. Further study of a larger patient series should be conducted to validate these results.

\section{Acknowledgements}

We thank Dr Gen Kobashi (National Institute of Radiological Sciences) for his help with statistical analysis and Ms. Masayo Terada (National Institute of Radiological Sciences) for her assistance in manuscript preparation.

\section{References}

1. Sudbo J: Novel management of oral cancer: a paradigm of predictive oncology. Clin Med Res 2: 233-242, 2004.

2. Casiglia J and Woo SB: A comprehensive review of oral cancer. Gen Dent 49: 72-82, 2001.

3. Leemans CR, Tiwari R, Nauta JJ, van der Waal I and Snow GB: Regional lymph node involvement and its significance in the development of distant metastases in head and neck carcinoma. Cancer 71: 452-456, 1993.

4. Leemans CR, Tiwari R, Nauta JJ, van der Waal I and Snow GB: Recurrence at the primary site in head and neck cancer and the significance of neck lymph node metastases as a prognostic factor. Cancer 73: 187-190, 1994

5. Greenberg JS, Fowler R, Gomez J, et al: Extent of extracapsular spread: a critical prognosticator in oral tongue cancer. Cancer 97: 1464-1470, 2003.

6. Ng SH, Yen TC, Liao CT, et al: 18F-FDG PET and CT/MRI in oral cavity squamous cell carcinoma: a prospective study of 124 patients with histologic correlation. J Nucl Med 46: 1136-1143, 2005 .
7. Sun R, Zhang JG and Guo CB: Establishment of cervical lymph node metastasis model of squamous cell carcinoma in the oral cavity in mice. Chin Med J 121: 1891-1895, 2008.

8. Martin CL, Reshmi SC, Ried T, et al: Chromosomal imbalances in oral squamous cell carcinoma: examination of 31 cell lines and review of the literature. Oral Oncol 44: 369-382, 2008.

9. Bockmuhl U, Petersen S, Schmidt S, et al: Patterns of chromosomal alterations in metastasizing and nonmetastasizing primary head and neck carcinomas. Cancer Res 57: 5213-5216, 1997.

10. Suzuki E, Imoto I, Pimkhaokham A, et al: PRTFDC1, a possible tumor-suppressor gene, is frequently silenced in oral squamouscell carcinomas by aberrant promoter hypermethylation. Oncogene 26: 7921-7932, 2007.

11. Liu CJ, Lin SC, Chen YJ, Chang KM and Chang KW: Arraycomparative genomic hybridization to detect genomewide changes in microdissected primary and metastatic oral squamous cell carcinomas. Mol Carcinog 45: 721-731, 2006.

12. Barrett MT, Scheffer A, Ben-Dor A, et al: Comparative genomic hybridization using oligonucleotide microarrays and total genomic DNA. Proc Natl Acad Sci USA 101: 17765-17770, 2004.

13. Xu C, Liu Y, Wang P, et al: Integrative analysis of DNA copy number and gene expression in metastatic oral squamous cell carcinoma identifies genes associated with poor survival. Mol Cancer 9: 143-148, 2010.

14. UICC: TNM classification of malignant tumours. 5h edition. pp20-24, 1997.

15. Weksberg R, Hughes S, Moldovan L, Bassett AS, Chow EW and Squire JA: A method for accurate detection of genomic microdeletions using real-time quantitative PCR. BMC Genomics 6: 180-189, 2005.

16. Gotoh T, Hosoi H, Iehara T, et al: Prediction of MYCN amplification in neuroblastoma using serum DNA and real-time quantitative polymerase chain reaction. J Clin Oncol 23: 5205-5210, 2005.

17. Huang Q, Yu GP, McCormick SA, et al: Genetic differences detected by comparative genomic hybridization in head and neck squamous cell carcinomas from different tumor sites: construction of oncogenetic trees for tumor progression. Genes Chromosomes Cancer 34: 224-233, 2002.

18. Lin SC, Chen YJ, Kao SY, et al: Chromosomal changes in betelassociated oral squamous cell carcinomas and their relationship to clinical parameters. Oral Oncol 38: 266-273, 2002.

19. Baldwin C, Garnis C, Zhang L, Rosin MP and Lam WL: Multiple microalterations detected at high frequency in oral cancer. Cancer Res 65: 7561-7567, 2005.

20. Sparano A, Quesnelle KM, Kumar MS, et al: Genome-wide profiling of oral squamous cell carcinoma by array-based comparative genomic hybridization. Laryngoscope 116: 735-741, 2006.

21. Li Y, Tondravi M, Liu J, et al: Cortactin potentiates bone metastasis of breast cancer cells. Cancer Res 61: 6906-6911, 2001.

22. Komatsu Y, Hibi K, Kodera Y, Akiyama S, Ito K and Nakao A: TAOS1, a novel marker for advanced esophageal squamous cell carcinoma. Anticancer Res 26: 2029-2032, 2006.

23. Luo ML, Shen XM, Zhang Y, et al: Amplification and overexpression of CTTN (EMS1) contribute to the metastasis of esophageal squamous cell carcinoma by promoting cell migration and anoikis resistance. Cancer Res 66: 11690-11699, 2006.

24. Chen YJ, Lin SC, Kao T, et al: Genome-wide profiling of oral squamous cell carcinoma. J Pathol 204: 326-332, 2004.

25. Gollin SM: Chromosomal alterations in squamous cell carcinoma of the head and neck: window to the biology of disease. Head Neck 23: 238-253, 2001.

26. Michalides R, van Veelen N, Hart A, Loftus B, Wientjens E and Balm A: Overexpression of cyclin D1 correlates with recurrence in a group of forty-seven operable squamous cell carcinomas of the head and neck. Cancer Res 55: 975-978, 1995.

27. Akervall JA, Michalides RJ, Mineta H, et al: Amplification of cyclin D1 in squamous cell carcinoma of the head and neck and the prognostic value of chromosomal abnormalities and cyclin D1 overexpression. Cancer 79: 380-389, 1997.

28. Coquelle A, Pipiras E, Toledo F, Buttin G and Debatisse M: Expression of fragile sites triggers intrachromosomal mammalian gene amplification and sets boundaries to early amplicons. Cell 89: 215-225, 1997.

29. Debatisse M, Coquelle A, Toledo F and Buttin G: Gene amplification mechanisms: the role of fragile sites. Recent Results Cancer Res 154: 216-226, 1998. 
30. Ciullo M, Debily MA, Rozier L, et al: Initiation of the breakagefusion-bridge mechanism through common fragile site activation in human breast cancer cells: the model of PIP gene duplication from a break at FRA7I. Hum Mol Genet 11: 2887-2894, 2002.

31. Reshmi SC, Roychoudhury S, Yu Z, et al: Inverted duplication pattern in anaphase bridges confirms the breakage-fusion-bridge (BFB) cycle model for 11q13 amplification. Cytogenet Genome Res 116: 46-52, 2007.

32. Weed SA and Parsons JT: Cortactin: coupling membrane dynamics to cortical actin assembly. Oncogene 20: 6418-6434, 2001.

33. Daly RJ: Cortactin signalling and dynamic actin networks. Biochem J 382: 13-25, 2004.

34. Rothschild BL, Shim AH, Ammer AG, et al: Cortactin overexpression regulates actin-related protein $2 / 3$ complex activity, motility, and invasion in carcinomas with chromosome 11q13 amplification. Cancer Res 66: 8017-8025, 2006.
35. Huang X, Godfrey TE, Gooding WE, McCarty KS Jr and Gollin SM: Comprehensive genome and transcriptome analysis of the 11q13 amplicon in human oral cancer and synteny to the 7F5 amplicon in murine oral carcinoma. Genes Chromosomes Cancer 45: 1058-1069, 2006.

36. Xia J, Chen Q, Li B and Zeng X: Amplifications of TAOS1 and EMS1 genes in oral carcinogenesis: association with clinicopathological features. Oral Oncol 43: 508-514, 2007.

37. Tomioka H, Morita K, Hasegawa $\mathrm{S}$ and Omura K. Gene expression analysis by cDNA microarray in oral squamous cell carcinoma. J Oral Pathol Med 35: 206-211, 2006.

38. Chen G, Bhojani MS, Heaford AC, et al: Phosphorylated FADD induces NF-kappaB, perturbs cell cycle, and is associated with poor outcome in lung adenocarcinomas. Proc Natl Acad Sci USA 102: 12507-12512, 2005. 